Domenico Carolei*

\title{
Accountability beyond Corporations: The Applicability of the OECD Guidelines for Multinational Enterprises to Non-profit Organisations
}

https://doi.org/10.1515/npf-2020-0024

Received May 21, 2020; accepted June 2, 2021

\begin{abstract}
The purpose of this article is to investigate the degree to which the OECD Guidelines for Multinational Enterprises - meant for businesses - apply to Non-Profit Organisations' (NPOs) operations and accountability. Based on a legal analysis of complaints handled by the National Contact Points (NCPs) in Norway, Switzerland, and the United Kingdom against NPOs, this paper shows that OECD Guidelines apply to certain types of NPOs, even if these organisations are by nature non-profit. It presents three conditions under which the OECD Guidelines can apply to NPOs: first, the NPO needs to operate in at least two countries; second, it must operate within a signatory state of the OECD Guidelines; and third, the OECD Guidelines violation must have occurred in relation to the business-activity of the NPO.
\end{abstract}

Keywords: Non-Profit-Organisations Accountability, OECD Guidelines for Multinational Enterprises, National Contact Points

\section{Introduction}

In 1976, the Organisation for Economic Co-operation and Development (OECD) adopted the Guidelines for Multinational Enterprises (OECD Guidelines) to promote a more responsible corporate approach to human rights among multinational enterprises and regulate their activities in developing countries (OECD 2011a, 2011b). As a multilateral instrument, the OECD Guidelines consist of voluntary recommendations addressed by governments to multinational corporations operating in or from adhering countries (OECD 2001, 9). This non-legally binding instrument sets standards of behaviour to promote responsible business in different fields: transparency, human rights, employment and

*Corresponding author: Domenico Carolei, Law Division, University of Stirling, Stirling, Scotland, E-mail: domenico.carolei@stir.ac.uk 
industrial relations, environment, anti-corruption, competition, and taxation (OECD 2001, 9). Governments adhering to the OECD Guidelines are required to set up a National Contact Point (NCP) which oversees the implementation of voluntary recommendations at the national level by performing two main factions: to advance the observance of OECD Guidelines among enterprises trough promotional activities, and to handle complaints (known as 'specific instances') against enterprises in case of non-compliance with the Guidelines (OECD 2001, 33). As a state-based non-judicial grievance mechanism, NCPs provide a forum for mediation and conciliation for resolving issues related to the non-observance of the OECD Guidelines by corporations (OECD 2001, 34-35). At the end of the mediation process, NCPs may issue a series of recommendations, not sanctions, consisting in suggested actions the parties are encouraged to take to resolve issues of non-observance of the OECD Guidelines. Since their adoption, the OECD Guidelines have contributed to enact and promote human rights responsibilities for businesses, despite their non-legally binding nature and the limited effectiveness of the NCP as e mechanism to remedy harms arising from corporate misconduct (Khoury and Whyte 2019; Reinert, Reinert, and Debebe 2016; Ruggie and Nelson 2015).

Although the OECD Guidelines were originally designed to address the behaviour of multinational enterprises, they have been recently used to file a series of human rights complaints against non-profit organisations (NPOs). ${ }^{1}$ The complaints have shown that NPOs are perceived to fail to respect human rights standards, despite NPOs operate within assumptions of good works, altruism and high standards of moral integrity. Simultaneously, these complaints have posed the question of whether the OECD Guidelines - meant for corporations - can be applicable to NPOs that are by definition non-profit making.

1 National Contact Point Norway, Initial Assessment and Final Conclusion, 129 Roma in Kosovo v. Norwegian Church Aid (NCA), on 26 September 2011; National Contact Point of Switzerland, Initial Assessment Specific Instance regarding the Fédération Internationale de Football Association (FIFA) submitted by the Building and Wood Workers' International (BWI) on 28 May 2015; National Contact Point of Switzerland, Initial Assessment Specific Instance regarding the Fédération Internationale de Football Association (FIFA) submitted by Americans for Democracy and Human Rights in Bahrain (ADHRB) on 11 February 2016; National Contact Point of Switzerland, Initial Assessment, Specific Instance regarding the World Wide Fund for Nature International (WWF) submitted by Survival International (SI) Charitable Trust on 20 December 2016; National Contact Point of Switzerland, Initial Assessment Specific Instance regarding the Roundtable for Sustainable Palm Oil (RSPO) submitted by Transformation for Justice (TuK) Indonesia on 31 May 2018; National Contact Point of United Kingdom, Initial assessment by the UK National Contact Point for the OECD Guidelines for Multinational Enterprises: complaint from IDI, EC and LICADHO against Bonsucro Ltd, on 25 September 2019. 
The purpose of this paper is to examine the degree to which the OECD Guidelines apply to NPOs, exploring how they can be subjected to an NCP's complaint about their adverse human rights impact. From an academic perspective, this investigation is relevant because a comprehensive examination of the NCP's complaints filed against NPOs has not been conducted yet. To date, there is only a legal commentary that considers the applicability of the OECD guidelines to Non-Governmental Organisations (NGOs) - a specific kind of NPO - and focuses on a single complaint (Carolei 2018). Other human rights lawyers have commented on some complaints about NPOs from the business and human rights law perspective (Fasterling 2019), and in the context of the refugee law (Janmyr 2013). From their end, civil society scholars have not yet examined the relevance of the OECD Guidelines for the NPO accountability discourse, paying attention exclusively to international voluntary instruments designed for the development and the humanitarian sector (Crack 2018; Deloffre 2016; Kennedy 2019). This paper is also pertinent because there is little policy guidance for NCPs on how they should handle complaints when it comes to applying the OECD Guidelines to non-corporate entities. Likewise, more guidance and clarity are needed for potential victims, and civil society organisations alike, that intend to use NCPs as a forum to settle disputes regarding an NPO's failure to comply with the OECD Guidelines. The paper's findings aim to shed light on these grey areas.

In order to evaluate the extent to which the OECD Guidelines apply to NPOs, this paper is structured as follows. Section 2 defines NPOs and explores their role in promoting corporate accountability under the OECD Guidelines. Section 3 examines those complaints filed against NPOs within the OECD system, exploring the evolution of the pertinent caselaw on the matter. ${ }^{2}$ Section 4 assesses the extent to which the OECD Guidelines can apply to NPOs, mapping out the key criteria that NPOs have to meet to be subjected to a complaint before NCPs. On a methodological level, this paper performs a legal analysis of the normative content of the OECD Guidelines and the decisions taken by NCPs in Norway, Switzerland, and the United Kingdom (UK) focusing on their legal reasoning. It relies on primary and secondary legal sources. It is argued that the OECD Guidelines apply to certain types of NPOs, even if they are by nature non-profit. To preview the key finding, a complaint under the OECD Guidelines can be filed against an NPO that a) it is registered or operating in adhering countries of the OECD Guidelines; b) it coordinates activities in various ways between

2 The term "caselaw" (in some jurisdictions also known as "jurisprudence") is the law created by the courts and other adjudicative bodies like NCPs. Even if legislative bodies (e.g. the parliament) enact most laws, courts can also develop the law. In common law systems, like the UK, the caselaw is an essential source of law. 
organisations based in multiple countries; c) it carries out business activities to achieve its non-profit aim.

\section{Defining Non-profit Organisations and Their Role in Promoting Accountability under the OECD Guidelines}

Defining NPOs is a challenging task because multiple definitions exist across disciplines and terms like NPOs, voluntary associations, third-sector organisations, and NGOs are frequently used as synonymous in the public discourse (Martens 2002). For the purpose of this paper, offering a definition of "NPO" matters for how NCPs handle different cases. From a legal perspective, non-profits are defined and constituted under domestic legislations. In legal scholarship, the label "NGO" is widely used by international lawyers and Article 71 of the 1945 United Nations Charter representing the first official mention of the term in international law. The term "NPO" includes all those entities that do not belong to either the government or the business sector, and it refers to a wide range of organisations including, but not limited to, NGOs, charitable organisations, faith-based organisations, professional associations, and foundations (Anheier 2005, 4-5). What distinguishes NPOs from business and governmental entities is the fact that these organisations are a) spontaneously and formally organised; b) private; c) self-governing; d) non-profit-distributing; and e) voluntary to some significant extent (Anheier 2005, 47-49). NPOs are profoundly different from each other, and differences can be observed in terms of geographical area, organisational type, and area of operation. In terms of geographical area, NPOs operate internationally, nationally and locally (Anheier 2005, 10). As to the organisational type, some NPOs are service providers, others are advocacy-based, and many combine the two (Anheier 2005, 174-175). Regarding the different types of NPOs, a common distinction is between self-benefitting and other-benefitting NPOs: the former organisations are primarily membership-based and designed to provide benefit solely to their members, whereas, the latter campaign for and/or provide service to marginalised groups who are unable to speak for themselves in policy forums (Anheier 2005, 354). Additionally, NPOs operate in different areas of operations (e.g. humanitarian relief, education, health etc.) and perform many functions in our society ranging from delivering social services to defending human rights and protecting vulnerable groups (Anheier 2005, 54).

When it comes to international human rights law, NPOs - especially INGOs play a crucial role in the overall promotion of human rights standards by holding 
states, businesses and international institutions accountable for their adverse human rights impact (Polizzi and Murdie 2019). The contribution of NPOs has also been particularly significant even in the context of the OECD Guidelines. In fact, it is estimated that around 350 complaints against corporations within the OECD system were submitted by community groups and NGOs in the past two decades (OECD Watch 'All cases'). A civil society network made up of different NPOs - called "OECD Watch"- researches aspects related to the implementation and effectiveness of the OECD Guidelines, and supports victims of corporate abuse who wish to file complaints before NCPs (OECD Watch 'About us'). In 2011, OECD Watch contributed to the revision of the OECD Guidelines strengthening provisions on human rights, supply chain responsibility and gas emission (OECD Watch, 'About us').

There can be no doubt that NPOs have significantly contributed to the development of OECD Guidelines and in promoting corporate accountability. However, as already noted in the introduction, there have been a number of complaints under the OECD Guidelines filed against NPOs. Apart from drawing attention to human rights violations caused by NPOs, these complaints have posed the question of whether the OECD Guidelines, meant for corporations, can apply to NPOs' operations and accountability.

\section{The Evolution of NCPs Caselaw}

In the last decade, NCPs have been called to handle a series of complaints against NPOs for their negative human rights impact. As will be shown below, the first complaint ever filed against an NPO was brought before the Norwegian NCP in 2011. The Norwegian NCP dismissed the complaint ruling out the possibility of applying the OECD Guidelines to a non-business entity. Subsequently, the Swiss NCP - and more recently the UK one - has been called several times to assess whether the Guidelines apply to NPOs paving the way to their application beyond corporations. The evolution of the NCP's caselaw is documented sequentially in the following subsections which are organised around national NCPs, with the Swiss NCP decisions representing the core evidence for how NPOs have become subject to regulations previously not applied to them.

\subsection{The Norwegian NCP (2011)}

In 2011, the Norwegian NCP received a complaint against the Norwegian Church Aid (NCA), a Norwegian-based NPO, managing a refugee camp in Kosovo, first on 
behalf of the United Nations Interim Administration Mission in Kosovo and later on behalf of the local government (NCP Norway 2011, 2).

The complainant, an American-based attorney representing 129 Roma in Kosovo, alleged that NCA was in breach of the OECD Guidelines as it failed to perform adequate due diligence in seeking to prevent exposure to serious and lethal health risks due to detrimental conditions in the camp that it managed (NCP Norway 2011, 1). The camp was allegedly located on contaminated land and previously used as a toxic waste dump site as it emerged from medical examinations on the inhabitants of the camps who experienced severe health problems. At the same time, the complainant claimed that NCA - formally not a business as such-should be considered as a multinational enterprise because it receives nearly half of its income from public funds and operates internationally (NCP Norway 2011, 5). Furthermore, the complainant argued that a reading of the wording 'companies or other entities' - under Chapter I (3) of the 2000 version of the OECD Guidelines - implies that entities other than commercial companies were intended to be covered by the Guidelines (NCP Norway 2011, 5). The NCA responded that their organisation in general, and the project in Kosovo more specifically, are humanitarian and not-for-profit (NCP Norway 2011, 5). Based on that, NCA could not be considered as a multinational enterprise under the OECD Guidelines.

The Norwegian NCP, after having consulted with the OECD Investment Committee at the Annual Meeting of the NCP, supported the view that NCA did not qualify as a multinational enterprise (NCP Norway 2011, 6; OECD 2011a, 2011b, 21). The complaint was, therefore, declared inadmissible because it fell beyond the scope of the Guidelines and the mandate of the NCP. The Norwegian NCP specified that, even if a precise definition of multinational enterprises is not required for the purposes of the Guidelines under Chapter I (3) under the 2000 version, there are no specific references to complaints against non-commercial organisations in the travaux preparatoires of the negotiations in 2000 (NCP Norway 2011, 6). Additionally, the NCP interpreted the scope of the OECD Guidelines as being part of the Investment Declaration, overseen by the OECD Investment Committee, and thus that they require a business nexus (NCP Norway 2011, 6). In this specific instance, the NCP noted that NCA was registered by Norwegian authorities in 2010 as a non-for-profit organisation, and not as a business enterprise, within the Register for Voluntary Organisations (NPC Norway 2011, 5).

\subsection{The Swiss NCP (2015-2018)}

In 2015, the Swiss NCP allowed a complaint brought by the Building and Wood Workers' International (BWI), an international union federation, against 
Fédération Internationale de Football Association (FIFA), a not-for-profit entity under Swiss law (NCP Switzerland 2015, 2). The complaint concerned alleged human rights violations of migrant workers by FIFA related to the construction of facilities for the FIFA 2022 World Cup in Qatar. According to BWI, FIFA failed to observe the OECD Guidelines by appointing Qatar as the host state for the FIFA 2022 World Cup in 2010 because, at the time, the human rights violations of migrant workers in Qatar were widely documented. BWI further sustained that FIFA failed to conduct an adequate human rights due diligence process aimed at identifying, preventing and mitigating potential adverse human rights impacts after appointing Qatar as the host state (NCP Switzerland 2015, 2-3).

Aside from rebutting the alleged violations of the Guidelines raised by the BWI, FIFA noted in their submission that "it was important to discuss how the OECD Guidelines could apply to FIFA, considering that they formally are an association registered in the Commercial Register under the Swiss Civil Code" (NCP Switzerland 2015, 4). At the same time, FIFA emphasised their commitment to respect human rights complying with business and human rights standards and other corporate social responsibility tools designed primarily for corporations, most notably the United Nations Guiding Principles on Business and Human Rights (NCP Switzerland 2015, 4).

The NCP ruled that the Guidelines were applicable to FIFA in this specific instance. The NCP noted that the Guidelines do not precisely define the term 'multinational enterprises' highlighting that the definition provided by Chapter I (4) is broad enough to encompass companies or other entities' that operate in all sectors of the economy, established in more than one country, and that coordinate their operations in various ways. Moreover, the NCP sustained that the Guidelines establish legally non-binding principles and standards for responsible business conduct, which is generally understood as the responsibility of entities involved in commercial activities (NCP Switzerland 2015, 4). Consequently, the key question that the competent NCP should determine - through a case-by-case analysis and in light of the concrete circumstances - is whether an entity is involved in commercial activities regardless of its legal form or sector of activity (NCP Switzerland 2015, 4).

In this specific complaint, the NCP observed that FIFA conducts international operations and has a multinational scope because it comprises of a variety of entities operating in multiple countries closely linked to one another to coordinate their global activities (NCP Switzerland 2015, 6). In addition to this, the NCP noticed that the bidding agreement signed between FIFA and Qatar was very comprehensive and included topics of commercial nature, such as media marketing rights, insurance and finance (NCP Switzerland 2015, 6). In light of FIFA's extensive involvement in the organisation of the 2022 World Cup, and given 
the contractual relationship with Qatar that can be seen as activities of commercial nature, the Swiss NCP concluded that, in this particular case, the OECD Guidelines apply to FIFA (NCP Switzerland 2015, 6).

One year later, the Swiss NCP was called to handle another complaint against FIFA filed by Americans for Democracy and Human Rights in Bahrain (ADHRB). ADHRB claimed that FIFA had allegedly violated the OECD Guidelines human rights provisions by allowing Sheikh Salman Al Khalifa from Bahrain to run for the FIFA presidency (NCP Switzerland 2016a, 2). The complainant claimed that FIFA failed to carry out adequate due diligence when conducting integrity checks on all the candidates for the FIFA Presidency (NCP Switzerland 2016a, 2). According to ADHRB, Sheikh Salman Al Khalifa was involved in the government crackdown of the 2011 peaceful protest by Bahraini citizens in support of human rights and democracy. More specifically, Sheikh Salman retaliated against athletes and sport clubs supporting the protest in quality of President of the Bahrain Football Association, General-Secretary of the Supreme Council for Youth and Sport, and Chairman of the inquiry committee into the behaviour of athletes during the protest (NCP Switzerland 2016a, 2).

In order to assess whether guidelines should apply to FIFA, the Swiss NCP applied the same criteria and reasoning adopted in the previous case against FIFA. This time, however, the NCP concluded that FIFA's activities allegedly in violation of the Guidelines, as argued by the claimant, were not linked to its commercial activities, and therefore fell outside the scope of the Guidelines (NCP Switzerland 2016a, 4). The NCP reached this conclusion based on the three main considerations. First, while FIFA is directly or indirectly involved in commercial activities, FIFA's status as a multinational enterprise must be considered on a case by case basis (NCP Switzerland 2016a, 4). Second, nothing had come to the attention of the Swiss NCP to believe that the purported actions of Sheik Salman were related to the commercial relationship between FIFA and the Bahrain Football Association (NCP Switzerland 2016a, 5). Third, the appointment procedure of candidates for the presidential election is an internal organisation issue, which is not directly linked to specific commercial activities of FIFA (NCP Switzerland 2016a, 5).

In December 2016, Survival International (SI), an INGO that campaigns for indigenous rights, filed a complaint against the World-Wide Fund for Nature (WWF), an independent foundation under Chapter 3 of the Swiss Civil Code (NCP Switzerland 2016b, 5). The complainant accused the WWF of facilitating violent abuse against Baka Pygmies, forcing them to leave their homeland in Cameroon to make way for a national reserve. According to SI, the WWF failed to conduct an adequate human-rights assessment with due diligence as it did not consult local communities directly affected by its actions when planning the national reserve (NCP Switzerland 2016b, 3). Also, SI documented a series of 
violent abuses against the Baka perpetrated by local eco-guards who were allegedly trained and supported both financially by the WWF (NCP Switzerland $2016 \mathrm{~b}, 4)$. The WWF objected to the allegations made by SI and accepted the NCP as a forum to mediate the dispute, although it disliked the idea of turning the OECD Guidelines meant for commercial companies "into a mechanism for resolving issues between two NPOs" (Barkham 2017).

To decide the matter, the NCP applied the same reasoning as in the previous complaints against FIFA and declared the OECD Guidelines applicable to WWF. The NCP's decision was based on two main reasons. Firstly, WWF International is a global network of organisations with offices in more than 80 countries, meeting the transnational nature criterion required by Chapter 1 (4) for the applicability of the OECD Guidelines (NCP Switzerland 2016b, 8). Secondly, even if WWF's operations may not per se qualify as being of a commercial nature, WWF's approach to conservation was to a certain extent market-based: for example, the income of the WWF's network is being generated from royalties and selling collectors' albums, and from the use of the panda emblem for the sale of environmentally friendly products (NCP Switzerland 2016b, 8). As to the outcome of this case, both NGOs initially accepted the OECD system as a conciliation forum in which to resolve the dispute, but the case did not reach a final decision because the mediation talks broke down (NCP Switzerland 2017).

Currently, the Swiss NCP is handling a complaint against the Roundtable on Sustainable Palm Oil (RSPO) on behalf of Transformation for Justice (TuK Indonesia), an Indonesian community rights group. The complaint concerned an unsolved land conflict in Indonesia dealt with by the RSPO's own complaint mechanism. In particular, TuK requested the Swiss NCP to support the elaboration of a clear and detailed action plan which needs to be taken to fix RSPO's complaint mechanism at the organisational level, rather than offering a mediation between the two parties and deal with merits of the complaint (NCP Switzerland 2018, 2).

The RSPO is a non-profit multi-stakeholder initiative registered as an association under Swiss law. In May 2018, the Swiss NCP declared the complaint admissible asserting that the RSPO, though not a traditional multinational enterprise, is nevertheless covered by the OECD Guidelines because it has a multinational scope, with technical offices based in several continents and, simultaneously, RSPO's income is generated by a prominent part (64\% in 2017) from commercial activities (NCP Switzerland 2018, 5). The most interesting part of the decision is how the NPC determined its competence over the complaint because even if RSPO has a legal registration in Switzerland, the operational control is based in Malaysia. Nevertheless, the Swiss NCP decided that "taking in account, that no other NCP would be competent to treat this specific instance, the Swiss NCP decides to offer its good offices to support direct discussions between the parties 
where deemed appropriate" (NCP Switzerland 2018, 4). The mediation process was successful, and the two parties agreed on an action plan for the legal review (NCP Switzerland 2019).

\subsection{The UK NCP (2019)}

More recently, the UK NCP received a complaint against the sugar MSI Bonsucro, a London-based company limited by guarantee which describes itself as a global multi-stakeholder non-profit organisation. The complaint alleges Bonsucro's failure to prevent land grabs in Cambodia by one of the participating companies (NCP UK 2019, para 2). This complaint was filed jointly by three civil society organisations: Inclusive Development International (IDI), Equitable Cambodia (EC) and Cambodian League for the Promotion and Defense of Human Rights (LICADHO). In their submission, the complainants explicitly refer to the previous Swiss NCP case, which considered the applicability of the guidelines to a similar multi-stakeholder initiative (RSPO). In September 2019, The UK NCP accepted the complaint for further examination highlighting that Bonsucro is a limited company based in UK with over 500 company members operating across more than 40 countries (NCP UK 2019, para 29). Essentially, the Guidelines apply to Bonsucro as its operations are inherently multinational. Bonsucro did not object to the application of the Guidelines; rather, it questioned whether the UK NCP is an appropriate forum to assess the behaviour of one of its subsidiaries operating overseas (NCP UK 2019, para 14). The UK NCP rejected Bonsucro's argument considering its forum as an appropriate venue to evaluate allegations regarding issues that are linked to the parent company's operations, products or services by a business relationship (NCP UK 2019, para 14). In September 2019, Bonsucro accepted the offer of mediation (Bonsucro 'Statement complaint under OECD Guidelines').

\section{The Application of the OECD Guidelines to NPOs}

The decisions of the Swiss and UK NCPs represent the core evidence as to how NPOs can be held accountable for non-compliance with the OECD Guidelines. The Swiss and UK decisions now make it a possibility for NPOs to be held accountable in front of NCPs in other countries. The Procedural Guidance to the OECD Guidelines makes clear that NCPs, in different countries, shall cooperate to ensure consistent interpretation and application of the Guidelines on the same issues (OECD 2019). The complaints examined above were filed against a variety of non-profit entities including a service-provider NGO (NCA), the international 
governing body of football associations (FIFA), multi-stakeholder initiatives (Bunsucro, and TuK), and a global NGO that campaigns in the field of nature conservation (WWF). Given that these organisations are incredibly different from each other (in terms of size, areas of activity, organisational structure, and type), one can wrongly assume that the OECD Guidelines apply to any kind of NPO. The latter assumption is, however, false because the above NCP's decisions were founded on the supposition that complaints against multinational entities, other than businesses, should be assessed by the competent NCP through a case-by-case analysis based on the concrete circumstances (NCP Switzerland 2016a, 5, 2016b; 7; NCP UK para 29). In essence, the Swiss and the UK NCPs rejected a universal and uniform approach on the matter, acknowledging the heterogeneity of the non-profit sector (ibid). Accordingly, NCPs are required to consider each case separately taking into account individual circumstances and attributes of an NPO. Based on the above examination of the complaints handled by NPCs, there are three criteria under which the OECD Guidelines can be applied to NPOs within the OECD system: a) the NPO must operate in more than one country; b) the NPO must operate or be registered within a signatory state of the OECD Guidelines; and c) the NPO must carry out business activities, even if it has a non-profit aim (Carolei 2018). An explanation of these three key criteria will help to circumscribe the applicability of the OECD Guidelines to certain types of NPOs.

\subsection{The NPO Must Operate Internationally}

Chapter 1 (4) of the OECD Guidelines specifies that entities must operate in more than one county or must coordinate activities in various ways among entities established in more than one country. So, the OECD Guidelines apply solely to entities, either profit or not-for-profit, operating in at least two countries. In other words, the Guidelines do not cover national NPOs working in one country neither do they cover those NPOs operating at a local level within a municipality or a state region.

There are a number of ways NPOs can operate in more than one country. INGOs meet this criterion as they coordinate activities across various entities situated in different countries. For instance, the WWF International coordinates activities from its global headquarters in Gland (Switzerland) and operates across 100 countries through national offices and associates (WWF 'How we're run'). In addition to INGOs, the transnational criterion can be met by other kinds of NPOs. For example, FIFA coordinates and supports 211 affiliated national associations worldwide, and these associations make up different confederations in different continents (FIFA 'Associations and Confederations'). As a multi-stakeholder 
initiative, Bonsucro is a global network with a diverse membership composed by businesses, civil society organisations and other stakeholders located in 40 countries (Bonsucro 'Membership'). In particular, Bonsucro's membership is composed by independent organisations with their own organisational structure and leadership, and membership includes Coca-Cola and WWF among others.

Given that Chapter 1(4) of the OECD Guidelines requires multinational entities to coordinate activities between organisations in 'various ways' it is irrelevant how an NPO coordinates global activities with its national branches, associates, affiliates or independent partners. Just as with multinational enterprises, the Guidelines apply to NPOs as long as the entity operates in more than one country, and regardless of their organisational structure and governance.

\subsection{The NPO Must Operate within a Signatory State of the OECD Guidelines}

The second criterion concerns the choice of the forum, where a complaint against an NPO for non-compliance with the Guidelines can be brought. Technically speaking, the OECD Guidelines is a non-legally binding multilateral instrument, meaning that complaints should be brought to the competent NCP set by the relevant signatory state. Accordingly, complaints must be filed against a multinational entity operating in or from adhering countries. The ordinary rule is that the complaint must be raised in the country where the alleged breach of the Guidelines occurred. Alternatively, if this country is not a signatory state of the OECD Guidelines, the issue should be raised in the country where the multinational entity is registered to carry out its activities abroad. To elaborate, the Swiss NCP in SI v. WWF has claimed its competence over this dispute because Cameroon was not a signatory state of the OECD Guidelines and WWF International, which was responsible for WWF operations in Cameroon, had its global headquarters in Switzerland (NCP Switzerland 2016b, 8). In a similar vein, the UK NCP considered that it was appropriate to consider allegations regarding Bonsucro occurring overseas that are linked to the UK-based parent company's operations, products or services by a business relationship (NCP UK 2019, para 14). But, the most interesting decision about the choice of the forum has been taken in TuKv RSPO by the Swiss NCP. Basically, the dispute arose in Indonesia, a non-adhering country of the OECD Guidelines, and RSPO's operational control is based in Malaysia. Since no operational unit of the RSPO is situated in Switzerland - despite being legally registered there - the Swiss NCP acknowledged that its degree of influence over the mediation could be limited. Nevertheless, the Swiss NCP decided to offer its offices 
to support the discussions between TuK and RSPO because no other NCP would be competent to deal with this specific instance (NCP Switzerland 2018, 4).

To sum up, complaints against NPO s should be brought to NCPs in the country where the alleged breach of the Guidelines occurred. If this country is not a signatory state of the OECD Guidelines, the issue should be raised before the NPO in those adhering countries where the NPO is registered to operate internationally.

\subsection{The NPO Must Carry out Business Activities}

As decided by the Swiss NCP in the first FIFA's complaint, the third criterion is that the NPO must carry out business activities. This criterion requires the relevant NCP to evaluate whether the NPO is involved in commercial activities, independently of its legal form and its sector of activities. Indeed, under chapter IV on Human Rights, the OECD Guidelines, they apply to all enterprises regardless of their size, sector, operational context, ownership and structure. Likewise, chapter 1 (4) of the OECD Guidelines specifies that the standards are applicable to enterprises operating in 'all sectors of the economy' with the aim of ensuring their widest possible observance.

When it comes to ascertaining whether an NPO carries out business activities, NCPs should conduct an accurate case-by-case analysis which considers individual peculiarities and attributes of the NPO. NPOs are not meant to generate profits and are not primarily guided by commercial goals. Even if NPOs are not primarily guided by commercial goals, they are not prevented from making profits. What national tax laws stipulate is that the profits made by an NPO cannot be distributed to the managers, stakeholders or employers. The prohibition to distribute profits to certain stakeholders is known as the "non-distribution constraint" and implies that NPOs reinvest the profits made or offer discounted services. Moreover, NPOs are allowed to conduct business activities and to make a profit, without altering their non-business character, provided that the business operation is to serve their non-profit-making aim. Put differently, non-profit activities and business activities are not antithetical categories, and they can be mutually compatible. There is a variety of ways in which NPOs carry out business activities in line with their non-profit purposes. A typical example in that respect is a market product made by the NPO's beneficiaries, which constitutes a business activity directly related to the NPO's principal mission (Lathlean 2016). A further example is an NPO that undertakes commercial activities intending to generate a surplus, which will fund its non-profit activities (Lathlean 2016).

It is worth specifying, however, that the mere fact that an NPO adopts a market-based approach may not be per se sufficient for declaring a complaint 
admissible before the competent NCP. Indeed, the Swiss NCP caselaw revealed that there must be a demonstrable link between the business activities and the allegations of non-compliance with the OECD Guidelines when it comes to filing a complaint. In the $A D H R B v$ FIFA case, the Swiss NCP held that the complaint was inadmissible because the alleged violations made against FIFA did not concern its commercial activities (NCP Switzerland 2016a, 4). On the contrary, the Swiss NCP declared the complaint submitted by BWI against FIFA admissible because the case was related to the commercial consequences of choosing Qatar as host nation for the 2022 World Cup (NCP Switzerland 2015, 6).

In sum, conditio sine qua non for the applicability of the Guidelines to NPOs is that the latter organisations carry out business activities. For a complaint to be declared admissible, the complainant should also demonstrate a clear link between the business activities, the alleged human rights and the related lack of due diligence under the OECD Guidelines.

\section{Conclusion}

The NPC caselaw has evolved rapidly in the past decade. Since when the Norwegian NCP dismissed the first case filed against an NPO in 2011, important developments have occurred within the OECD system with the complaints against FIFA and the WWF paving the way to the application of the Guidelines to NPOs. Although they were not primarily designed for them, the OECD Guidelines apply now to NPOs and can be used to hold a broader range of transnational entities accountable regardless of their nature as a profit or not-for-profit organisation. From a policy perspective, these decisions carry significant implications and might lead to a policy debate towards a reform project of the OECD Guidelines. The last reform of the Guidelines was undertaken in 2011. The 2011 version of the OECD Guidelines specifies, through a commentary on "Concepts and Principles" (Part I, para 4), that a precise definition of multinational enterprises is not required for the purpose of this instrument. Future reforms could recognise, more explicitly and on a normative level, the applicability of the OECD Guidelines to NPOs within this section on "Concepts and Principles.” From a regulatory perspective, the increased usage of the OECD Guidelines to hold NPOs accountable for their adverse human rights performance is a sign of a lack of adequate national regulatory standards at the domestic level (Anheier and Toepler 2019). Similarly, at the international level, no instrument outlines the human rights responsibilities of NPOs and holds them accountable (Lindblom 2005). In this legal vacuum, the OECD Guidelines is a precious tool to ensure human rights compliance filling a regulatory gap. Some of the complaints examined above (Bunsucro, and TuK) ended in mediation, 
suggesting that OECD Guidelines represent a promising way to address human rights issues of NPOs. Simultaneously, the fact that mediation talks failed in other instances (SI vWWF) indicates that the OECD Guidelines should not be viewed as a panacea for issues of NPO accountability and present limitations due to the voluntary nature of the mediation process. Far from representing an ideal accountability system, the OECD Guidelines represent a new avenue to assess the human rights performance of NPOs. The Guidelines should work hand and glove with existing domestic regulations (state and self-regulation) and new accountability watchdogs, like the establishment of international ombudsmen proposed in 2018 as a response to the accountability and safeguarding failures that occurred in Oxfam and Save the Children. Future research should shed light on whether human rights accountability mechanisms, typically designed for corporations, can be used to hold NPOs accountable. For example, the United Nations Global Compact has been signed by over 4,000 non-business entities including NPOs (UN Global Compact, 'Our Participants'). The FIFA, whose human rights performance was scrutinised under the Guidelines by the Swiss NCP, has embraced the United Nations Guiding Principles on Human Rights (FIFA, 2017). These developments deserve attention by non-profit and human rights scholars because NPO compliance with human rights standards is an important part of building a better and safer world.

\section{References}

Anheier, H. K. 2005. Nonprofit Organisations: An Introduction - Theory, Management and Policy. London and New York: Routledge.

Anheier, H. K., and S. Toepler. 2019. "Policy Neglect: The True Challenge to the Nonprofit Sector." Nonprofit Policy Forum 10 (4): 1-9.

Barkham, P. 2017. "Human Rights Abuses Complaint against WWF to Be Examined by OECD." The Guardian. www.theguardian.com/environment/2017/jan/05/oecd-to-examine-complaintagainst-wwf-over-human-rights-abuses-in-cameroon (accessed April 30, 2020).

Bonsucro. "Membership." www.bonsucro.com/bonsucro-members-2/ (accessed May 1, 2020).

Bonsucro. "Statement: Complaint under OECD Guidelines for Multinational Enterprises." https://www.bonsucro.com/statement-complaint-under-oecd-guidelines-formultinational-enterprises-2/ (accessed February 9, 2021).

Carolei, D. 2018. "Survival International vs WWF: Using the OECD Guidelines for Multinational Enterprises as a Means of NGO Accountability." Human Rights Law Review 18 (2): 371-84.

Crack, A. M. 2018. "The Regulation of International NGOS: Assessing the Effectiveness of the INGO Accountability Charter." Voluntas 29 (2): 419-29.

Deloffre, Z. M. 2016. "Global Accountability Communities: NGO Self-Regulation in the Humanitarian Sector.” Review of International Studies 42 (4): 724-47. 
Fasterling, B. 2019. "Whose Responsibility? The Responsibility of the Business Enterprises to Respect Human Rights." In In Accountability, International Business Operations and the Law: Providing Justice for Corporate Human Rights Violations in Global Value Chains, edited by L. Enneking, I. Giesen, A. J. Schaap, C. Ryngaert, F. Kristen, and L. Roorda, 18-38. London and New York: Routledge.

FIFA. "Associations and Confederations." www.fifa.com/associations/ (accessed May 5, 2020). Janmyr, M. 2013. Protecting Civilians in Refugee Camps: Unable and Unwilling States, UNHCR and International Responsibility. Nijhoff: Brill.

Kennedy, D. 2019. "The Inherently Contested Nature of Non-governmental Accountability: The Case of HAP International." Voluntas 30: 1393-405.

Khoury, S., and D. Whyte. 2019. "Sidelining Corporate Human Rights Violations: The Failure of the OECD's Regulatory Consensus.” Journal of Human Rights 18: 363-81.

Lathlean, L. 2016. "Making a Profit as a Not-For-Profit: Undertaking Commercial Activities." Third Dimension 13: 2-4.

Lindblom, A. 2005. Non-Governmental Organisations in International Law. Cambridge: Cambridge University Press.

Martens, K. 2002. “Mission Impossible. Defining Nongovernmental Organizations.” Voluntas 13 (3): 271-85.

National Contact Point Norway. 2011. Initial Assessment and Final Conclusion. 129 Roma in Kosovo V. Norwegian Church Aid (NCA).

National Contact Point of Switzerland. 2015. Initial Assessment, Specific Instance Regarding the Fédération Internationale de Football Association (FIFA) Submitted by the Building and Wood Workers' International (BWI).

National Contact Point of Switzerland. 2016a. Initial Assessment, Specific Instance Regarding the Fédération Internationale de Football Association (FIFA) Submitted by Americans for Democracy and Human Rights in Bahrain (ADHRB).

National Contact Point of Switzerland. 2016b. Initial Assessment, Specific Instance Regarding the World-Wide Fund for Nature International (WWF) Submitted by Survival International Charitable Trust (SI).

National Contact Point of Switzerland. 2017. Final Statement, Specific Instance Regarding the World-Wide Fund for Nature International (WWF) Submitted by the Survival International Charitable Trust.

National Contact Point of Switzerland. 2018. Initial Assessment, Specific Instance Regarding the Roundtable for Sustainable Palm Oil (RSPO) Submitted by Transformation for Justice (TuK).

National Contact Point of Switzerland. 2019. Final Statement, Specific Instance Regarding the Roundtable for Sustainable Palm Oil (RSPO) Submitted by TuK Indonesia (TuK).

National Contact Point of United Kingdom. 2019. Initial Assessment by the UK National Contact Point for the OECD Guidelines for Multinational Enterprises: Complaint from IDI, EC and LICADHO against Bonsucro Ltd.

OECD Watch. "About Us." www.oecdwatch.org/about-us (accessed April 28, 2019).

OECD Watch. 2020. "All Cases.” https://complaints.oecdwatch.org/cases/all-cases/ casesearchview?b_start:int=330 (accessed November 17, 2020).

Organisation for Economic Cooperation and Development. 2001. The OECD Guidelines for Multinational Enterprises: Text, Commentary and Clarifications. Paris: OECD.

Organisation for Economic Cooperation and Development. 2011a. OECD Guidelines for Multinational Enterprises, 2011 ed. Paris: OECD. 
Organisation for Economic Cooperation and Development. 2011b. OECD Guidelines for Multinational Enterprises: Report by the Chair of the 2010 Meeting of the National Contact Points. Paris: OECD.

Organisation for Economic Cooperation and Development. 2019. Guide for National Contact Points on Coordination when Handling Specific Instances. Paris: OECD.

Polizzi, M., and A. Murdie. 2019. "NGOs and Human Rights." In Routledge Handbook of NGOs and International Relations, edited by T. Davies, 251-66. London and New York: Routledge.

Reinert, K. A., O. T. Reinert, and G. Debebe. 2016. "The New OECD Guidelines for Multinational Enterprises: Better but Not Enough.” Development in Practice 26 (6): 816-23.

Ruggie, J., and T. Nelson. 2015. "Human Rights and the OECD Guidelines for Multinational Enterprises: Normative Innovations and Implementation Challenges.” Working Paper N. 66. Harvard University. Corporate Social Responsibility Initiative.

World-wide Fund for Nature. “How We're Run.” https://wwf.panda.org/discover/about_wwf/ how_were_run/? (accessed February 2, 2021). 